Klaus Kümmerer · Maximilian Hempel Editors

\title{
Green and Sustainable Pharmacy
}




\section{Contents}

\section{Part I General Aspects}

1 Why Green and Sustainable Pharmacy? . . . . . . . . . . . . . . 3 Klaus Kümmerer

2 Pharmaceuticals in the Environment: Moving from a Problem to a Solution . . . . . . . . . . . . . . . 11 John P. Sumpter

3 Pharmaceuticals in Society . . . . . . . . . . . . . . . . 23 David J. Triggle

4 Green(er) Pharmacy . . . . . . . . . . . . . . . . . . . . . . 37

James H. Clark, Simon W. Breeden, and Louise Summerton

5 Creating a Sustainability Culture - A (Human Resources) Management Perspective for Sustainable Pharmacy . . . . . . . 61 Michael Läufer

6 Reducing the Ecological Footprint of Pharmaceutical Usage: Linkages Between Healthcare Practices and the Environment 77 Christian G. Daughton and Ilene S. Ruhoy

Part II Development, Synthesis and Production and Distribution of Pharmaceuticals

7 Ecopharmacostewardship - A Pharmaceutical Industry Perspective 105 David Taylor

8 Protein and Peptide Therapeuticals: An Example of "Benign by Nature" Active Pharmaceutical Ingredients . . . . . 127 Jürg Oliver Straub

9 Rational Design of Molecules by Life Cycle Engineering _ . . . . 135 Klaus Kümmerer 
Part III Use and Disposal of Pharmaceuticals

10 Options for a More Environmentally Friendly Handling of Pharmaceuticals . . . . . . . . . . . . . . . . . . . . 149

Konrad Götz and Jutta Deffner

11 Disposal of Pharmaceutical Waste in Households -

A European Survey . . . . . . . . . . . . . . . . . . . . . . . . . . 165

Gerald Vollmer

12 Pharmaceutical Waste: The Patient Role . . . . . . . . . . . . . . . 179

Staffan Castensson and Anders Ekedahl

13 Forecast of Pharmaceutical Consumption in the Netherlands Using Demographic Projections . . . . . . . . . . . . 201 Monique van der Aa and Geertjan Kommer

Part IV Emission Management

14 Point Sources of Human Pharmaceuticals into the Aquatic Environment

Kevin V. Thomas and Katherine H. Langford

15 Pharmaceuticals for Human Use: An Integrated Strategy for Reducing the Contamination of Water Bodies Florian Keil

16 Experiences with the Swedish Environmental Classification Scheme Åke Wennmalm and Bo Gunnarsson

Part V Incentives, Regulation and the Market

17 European Regulations

Eleftheria Kampa, Thomas Dworak, Cornelius Laaser, and

Rodrigo Vidaurre

18 Regulation and the Market-Incentives

Benoît Roig and Evelyne Touraud

19 Do Pharmaceuticals in the Environment Present an

Investment Risk?

Andreas Holzer

\section{Part VI Outlook}

20 Sustainable Health Products and Service Solutions in the

Year 2050

Ludwig Metz and Klaus Kümmerer 
21 Summary and Outlook . . . . . . . . . . . . . . . . . . . . . . . . . 299 Klaus Kümmerer Maximilian Hempel, Hans-Christian Schaefer, and Florian Keil

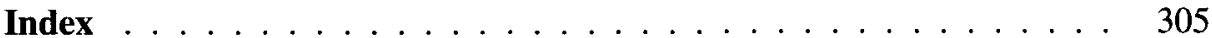

